\title{
Smart polymers for cell therapy and precision medicine
}

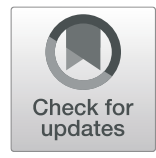

Hung-Jin Huang ${ }^{1 \dagger}$, Yu-Liang Tsai ${ }^{1 \dagger}$, Shih-Ho Lin ${ }^{1 \dagger}$ and Shan-hui Hsu ${ }^{1,2,3^{*}}$

\begin{abstract}
Soft materials have been developed very rapidly in the biomedical field over the past 10 years because of advances in medical devices, cell therapy, and 3D printing for precision medicine. Smart polymers are one category of soft materials that respond to environmental changes. One typical example is the thermally-responsive polymers, which are widely used as cell carriers and in 3D printing. Self-healing polymers are one type of smart polymers that have the capacity to recover the structure after repeated damages and are often injectable through needles. Shape memory polymers are another type with the ability to memorize their original shape. These smart polymers can be used as cell/ drug/protein carriers. Their injectability and shape memory performance allow them to be applied in bioprinting, minimally invasive surgery, and precision medicine. This review will describe the general materials design, characterization, as well as the current progresses and challenges of these smart polymers.
\end{abstract}

Keywords: Smart materials, Bioprinting, Cell therapy, Tissue engineering, Precision medicine

\section{Background}

Soft materials with similar shear modulus or mechanical strength to human body tissues have been highly focused in the decades, especially those soft materials with unique properties that we called "smart polymeric materials". Since the concept of one-size-fits-all was outdated, scientists and engineers have designed smart materials into tunable and personalized products to overcome many limitations during the heterogeneous environment in the human body. Smart materials, also known as responsive materials, are synthetic materials with one or more properties that can be significantly altered in a controlled manner by external stimuli [1]. Polymeric smart materials are most commonly used in the biomedical field, owing to not only introducing the high biocompatibility from natural polymers [2] but also the tunable and functional properties from synthetic polymers [1]. There are many external stimuli for smart materials, including temperature [3], redox reactions [4],

\footnotetext{
* Correspondence: shhsu@ntu.edu.tw

${ }^{\dagger}$ Hung-Jin Huang, Yu-Liang Tsai and Shih-Ho Lin contributed equally to this work.

${ }^{1}$ Institute of Polymer Science and Engineering, National Taiwan University,

No. 1, Sec. 4 Roosevelt Road, Taipei 10617, Taiwan, Republic of China

${ }^{2}$ Research and Development Center for Medical Devices, National Taiwan

University, Taipei, Taiwan

Full list of author information is available at the end of the article
}

humidity [5], electric or magnetic field [6], $\mathrm{pH}$ changes [7], and light intensity [8]. Those materials with different triggering mechanisms were used for various biomedical applications, including biosensors [9], controllable drug delivery [10, 11], tissue repairing [12], local injection, cancer cell separators, minimally invasive surgery, and 3D bioprinting [13], etc. The tunable properties and environmental responses of the smart polymeric materials provide the opportunity to design personalized biomedical products. This review paper will emphasize three kinds of typical polymeric smart materials, including stimulus-responsive, self-healing, and shape memory in materials. The review also discusses some recent applications in precision medicine, such as 3D bioprinting, cell therapy, and tissue engineering.

Stimulus-responsive materials have been employed to develop novel medical devices for minimally invasive procedures. For instance, thermoresponsive and $\mathrm{pH}-$ sensitive hydrogels are commonly used for cardiac therapies at low local pH of an infarcted area [14]. By exposing to stimuli, the responsive polymeric materials show a local response, which can be a trigger for intracellular drug delivery for tissue targeting [15]. Moreover, self-healing hydrogels are 3D chemical or physical reversible network that can recover the original morphology after damages. Dynamic linkages dominate the 
dissociation and recombination processes and endow the self-healing property similar to human tissue repairing [16]. Therefore, self-healing hydrogels with appropriate viscoelasticity and high water contents are employed to mimic the extracellular matrix for providing a suitable environment for cell culture. Self-healing hydrogels have achieved significant success in central nervous rescued, vascular tissue reconstruction, and the anti-cancer drug delivery, etc. [17-19]. In addition, shape memory materials (SMMs) are commonly divided into two groups, shape memory alloys (SMAs) and shape memory polymers (SMPs). After being severely and quasi-plastically distorted [20], SMMs can recover to their original shapes with proper stimuli. SMAs are usually utilized for cardiovascular stents or orthodontic devices [21], whereas SMPs can be used in cardiac valves, kidney dialysis, and neuroprosthetics [22]. SMPs with biocompatibility and biodegradability are potential materials for many advanced applications, such as soft robotics, artificial skin, and 4D printing in the future [23-25].

Precision medicine, also called personalized medicine, is an avant-garde field of health care that relies on a person's clinical, genetic, and environmental conditions. To realize precision medicine, it needs to integrate a wide range of fields, including smart biomaterials, pathology, large-scale biological databases, and medical devices [26]. The development of smart polymeric materials that exhibit good biocompatibility and adjustability may accelerate the progress of precision medicine because the properties of smart polymeric materials can be designed to own properties highly specific for individuals [14].

Three core values of precision medicine are compiled for the relationship between precision medicine and materials in Fig. 1, "temporal", "personal", and "spatial". The temporal perspective concerns the balance between the treatment time of the patients and the degradation

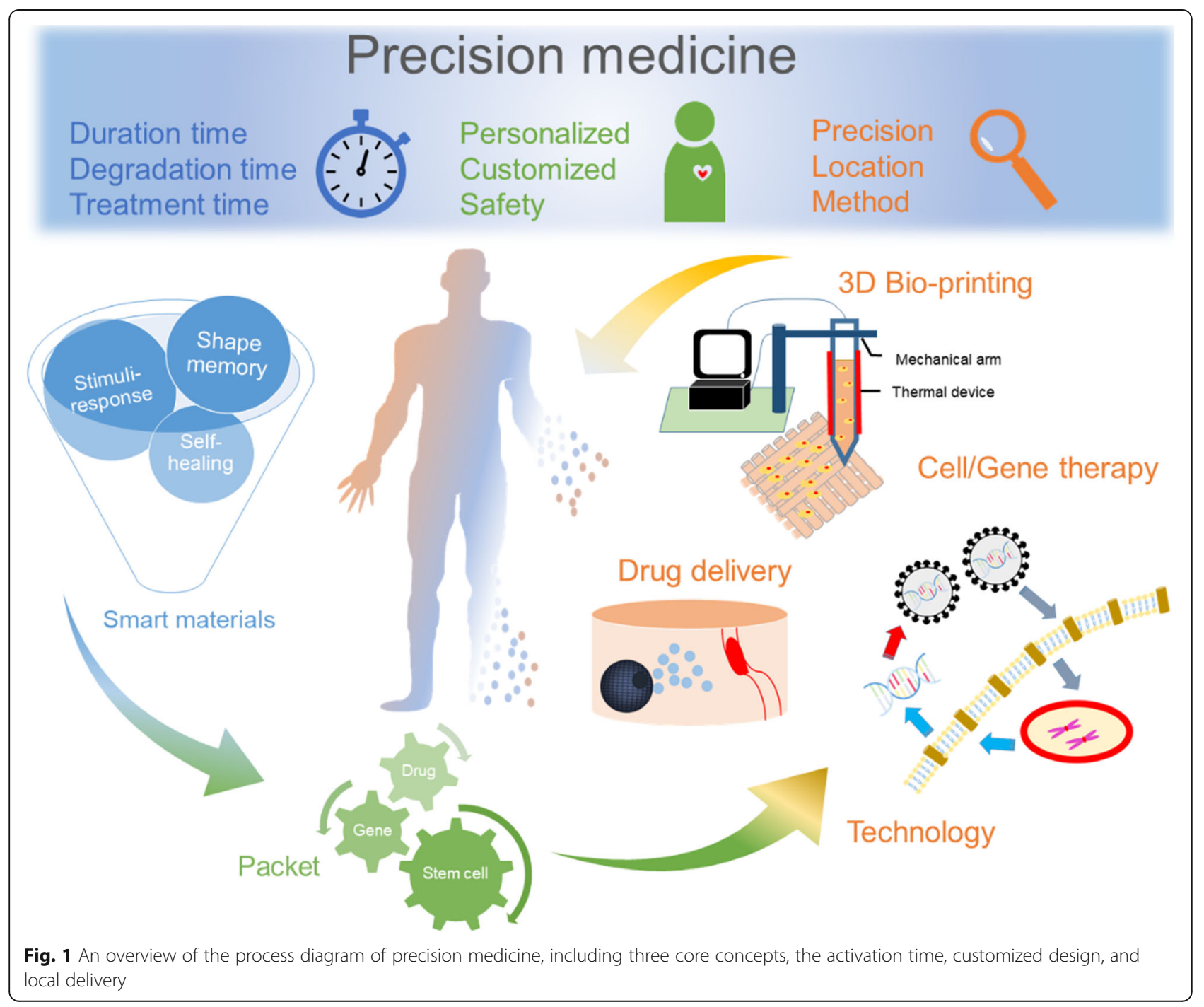


time of the smart polymeric materials. The polymeric materials for in vivo applications, such as drug carriers, wound dressing, and bioglue [27], are either degradable or absorbable after the treatment, and the degradation products should not be toxic or harmful. From the personal perspective, the smart polymeric materials should be capable of carrying patients' stem cells or genes for cell/gene therapy [28]. From the spatial perspective, the materials should respond to particular stimuli and release drugs at designed locations. To fulfill these three perspectives, the combination of technology and materials is highly demanded. For example, 3D bioprinting of shape memory materials is one good strategy to prepare customized biomedical devices, and surgeons will be able to utilize the patient-orientated product to perform minimally invasive surgery [15]. In this review, several smart materials will be introduced in the aspects of limitations and biomedical applications.

\section{Smart polymeric materials in biomedicine}

Smart polymeric materials with stimuli-responsive, selfhealing, and shape memory behaviors can be applied in the biomedical field. The combination of the three features is beneficial in precision medicine. The important concepts and the advantages of smart polymeric materials with three categories in precision medicine are summarized in Table 1. In the following sections, we summarize the compositions, mechanisms, and applications of different types of smart polymeric materials.

\section{Responsive (thermal / photo) polymers: Thermoresponsive polymers}

Pluronics, also known as Poloxamers, are nonionic triblock copolymers consisting of a central hydrophobic polypropylene oxide (PPO) block flanked by hydrophilic polyethylene oxide (PEO) blocks. Due to the hydrophobic interaction, Pluronics self-assemble in the aqueous solution, and the micellization conditions of Pluronics are dominated by both concentration and temperature [53, 54]. The hydrophobic segments of Pluronic aggregate in order to minimize surface tension when concentration is higher the critical micelle concentration $(\mathrm{CMC})$ and the temperature is lower critical solution temperature (LCST) $[55,56]$. The amphiphilic polymers also show some weaknesses such as rapid dissolution, short residence time, and weak mechanical strength [57]. To solve the problems, the modification of hydroxyl groups at the end of the chain provides a good opportunity to overcome the previous mentioned disadvantages [57]. Pluronics with different ratios of bioinert PEO and PPO segments (L121, P123, F127, etc.) show low foreign body reactions and have tunable properties for customized precision medicine. Taken together, the Pluronic and its derivatives display wide-range usages such as tissue regeneration scaffolds [58], antineoplastic delivery [59], super-tough hydrogel [60], and antibacterial adhesive [61].

Poly (N-isopropyl acrylamide) (PNiPAAm) is a type of thermosensitive polymers that undergoes a hydrophilichydrophobic transition in water at the LCST around $32^{\circ} \mathrm{C}$. The PNiPAAm demonstrates hydrophilic behavior for hydrogen bonds between water molecules and amide groups when the temperature is below the LCST. When the temperature is above LCST, PNiPAAm becomes hydrophobic since water molecules are expelled from the hydrophilic region of PNiPAAm [29, 30]. With the thermoresponsiveness between room temperature and physiological temperatures, PNiPAAm has been employed to design a variety of smart biomaterials, such as drug or cell delivery vehicles, imaging or sensing, fiber mats for cell recovery, and strain sensors [32, 62].

Polyurethane nanoparticles (PU NPs) with different compositions of biodegradable oligodiols as the soft segment have been reported to be thermoresponsive. The morphological change and rheological behavior of PU NPs are thermal dependents because of different degrees of crystallinity and strength of hydrogen bonding in soft segment compositions. With the thermoresponsive feature, PU NPs can be designed as cell delivery vehicles, biodegradable stents, or bioinks [33, 34, 48].

\section{Responsive (thermal / photo) polymers: Photoresponsive polymers}

Photoresponsive polymers, the light-mediated materials, benefit from precisely spatiotemporal tunability. The common photochemical reactions include bond formation, cleavage, isomerization, and molecular rearrangement [63]. The mechanical properties of photoresponsive polymers can be manipulated by different types of light sources, light dosages, and photoinitiators. Photoinitiators, which are widely-used in bioengineering applications, are Irgacure 2959 (2-Hydroxy-1-(4-(2-hydroxyethoxy)phenyl)-2-methyl-1-propano), LAP (lithium phenyl-2,4, 6-trimethylbenzoylphosphinate), eosin-Y, and VA-086 (2,2'-Azobis[2-methyl-N-(2-hydroxyethyl)propionamide]) due to low cytotoxicity, and water solubility [64-66]. The exposure time and the intensity of photo-triggered process, which can be precisely controlled, are two major advantages of using photoresponsive polymers as biomaterials $[67,68]$. Epoxy resins were one of the earliest photoresponsive polymers in dental applications, namely, dental restoratives and fillers. The resins allowed in-situ polymerization and on-site treatments $[36,69]$. Acylate-based monomers undergo radical polymerization through ultraviolet (UV) light exposure to produce thin films for biomedical applications [68]. O-nitrobenzyl succinate and disulfide were photosensitive moieties, which were utilized to facilitate the synthesis of micelles and 
Table 1 The mechanisms, components, and applications of smart polymers in precision medicine

\begin{tabular}{|c|c|c|c|c|c|}
\hline Category & Mechanism & Component & Applications & Benefit & Reference \\
\hline \multirow{12}{*}{$\begin{array}{l}\text { Stimuli } \\
\text { response }\end{array}$} & \multirow[t]{7}{*}{ Temperature } & \multirow[t]{4}{*}{ NiPAAm } & Biomolecule carriers & Injectable & {$[29]$} \\
\hline & & & Wound dressing & $\begin{array}{l}\text { Long-term antimicrobial and anti- } \\
\text { protein absorption }\end{array}$ & {$[30]$} \\
\hline & & & $\begin{array}{l}\text { Sensing, imaging, and } \\
\text { carrier }\end{array}$ & Multifunctional sensing and imaging & {$[31]$} \\
\hline & & & Cell culture platform & Bioactive cell recovery & {$[32]$} \\
\hline & & \multirow[t]{2}{*}{ PU } & Cell or drug carrier & Highly tunable & {$[33]$} \\
\hline & & & $\begin{array}{l}\text { Neural tissue } \\
\text { engineering }\end{array}$ & Printable bioink & [34] \\
\hline & & Pluronic & Drug delivery & Injectable, thermo-responsive & {$[35]$} \\
\hline & \multirow[t]{5}{*}{ Photo } & Epoxy resins & $\begin{array}{l}\text { Dental restorative or } \\
\text { fillers }\end{array}$ & Durable, easy operation & {$[36]$} \\
\hline & & \multirow[t]{3}{*}{ GelMA } & Cell culture platform & Printable multi cells & {$[37]$} \\
\hline & & & $\begin{array}{l}\text { Cartilage tissue } \\
\text { engineering }\end{array}$ & Animal model & {$[38]$} \\
\hline & & & Bone tissue engineering & $\begin{array}{l}\text { Structurally stable for large bone } \\
\text { defects }\end{array}$ & [39] \\
\hline & & $\mathrm{PU}$ & $\begin{array}{l}\text { Neural tissue } \\
\text { engineering }\end{array}$ & Printable soft bioink & {$[8]$} \\
\hline \multirow[t]{7}{*}{ Self-healing } & \multirow[t]{4}{*}{$\begin{array}{l}\text { Physical } \\
\text { interaction }\end{array}$} & Poly(styrene-acrylic acid) & Artificial cartilage or skin & High mechanical strength & {$[40,41]$} \\
\hline & & Poly(glyceryl amine) & Dermal drug delivery & Strong penetration ability & [42] \\
\hline & & Polyaniline, phytic acid & Wearable electronics & Mechanically robust & [43] \\
\hline & & $\begin{array}{l}\text { Silver-nucleoside complex [Ag(I)- } \\
\text { (N3-cytidine)2] }\end{array}$ & Metallo-DNA & Thixotropic self-healing & [44] \\
\hline & \multirow[t]{3}{*}{$\begin{array}{l}\text { Chemical } \\
\text { covalent bond }\end{array}$} & Polyurea, HA & $\begin{array}{l}\text { Polyurea flooring } \\
\text { systems }\end{array}$ & Crack repair & {$[45]$} \\
\hline & & HA, glycol chitosan & $\begin{array}{l}\text { Cartilage tissue } \\
\text { engineering }\end{array}$ & Biocompatibility & [46] \\
\hline & & Graphene nanoplate & Electronic devices & Electrical conductivity & {$[47]$} \\
\hline \multirow[t]{5}{*}{$\begin{array}{l}\text { Shape } \\
\text { memory }\end{array}$} & \multirow[t]{2}{*}{ Temperature } & PU & $\begin{array}{l}\text { Shape memory stents or } \\
\text { scaffolds }\end{array}$ & Biodegradability & {$[48]$} \\
\hline & & N,N-dimethylacrylamide & $\begin{array}{l}\text { Artificial intervertebral } \\
\text { disk }\end{array}$ & Strong interface & {$[49]$} \\
\hline & \multirow[t]{2}{*}{ Water } & PU & Bone tissue engineering & Printable bioink & {$[50]$} \\
\hline & & Cellulose & Pressure sensor & Zero poisson ratio, durable & [51] \\
\hline & $\mathrm{pH}$ & Alginate & Bioglue & Adhesive & {$[52]$} \\
\hline
\end{tabular}

particles for controlled drug delivery vehicles [70, 71]. A double-threaded rotaxane dimer with $\alpha$-cyclodextrin and stilbene was an example of photo-triggered moieties that could potentially lead to the development of artificial muscles [72]. A photosensitive PU hydrogel was also reported to be a promising candidate for 3D bioprinting, particularly in the field of neural tissue engineering [8]. Gelatin methacryloyl (GelMA) was a widely used semisynthetic biomaterial with gelatin and methacryloyl moieties, which rendered GelMA photocrosslinkable by UV light or visible light [37, 73]. Different cells could be loaded in GelMA hydrogels for tissue engineering or
3D bioprinting [74-76]. In addition, GelMA cryogels were fabricated as a matrix for tissue engineering and trigger-release cell therapy [38, 77]. GelMA is one of the most popular photoresponsive biomaterials because of convenient synthesis, biocompatibility, printability, and the translational results from in vivo experiments to realize cell therapy and precision medicine.

\section{Self-healing polymers}

Self-healing polymers are one classic type of smart polymers that can recover the structure after repeated damages and restoring the original functionality [13]. Self-healing 
hydrogels are of particular interest because of high water contents and controllable rheological properties [78, 79]. With the as mentioned features, self-healing hydrogels mimic extracellular matrix, making this class of smart polymers competitive candidates for biomedical applications [16].

Two mechanisms of self-healing hydrogels are proposed to explain the dynamic and reversible bonding, shown in Fig. 2. They are non-covalent interactions and dynamic covalent bonds. Non-covalent interactions include hydrogen bond [40], host-guest interactions [42], electrostatic interactions [43], $\pi-\pi$ interactions [80], and hydrophobic interactions [44]. The weak intermolecular forces of noncovalent interactions facilitate the reversible assembly and disassembly of self-healing hydrogels. Dynamic covalent bonds include disulfide bonds [45], imine bonds [46], boronate ester bonds [81], and Diels-Alder reactions [47].

The rheological properties of self-healing hydrogels can be specifically tuned, and the hydrogels that possess shear-thinning behavior are injectable. After being injected via needles, hydrogels remain their structures; thus, It is possible to load patients' cells in the hydrogels for cell therapy and precision medicine [82]. Additionally, self-healing hydrogels were reported to be wound dressings, strain sensors, cell/drug/protein carriers, and bioelectronics devices [83-89]. Chitosan-based and hyaluronic acid-based hydrogels attract the most attention in self-healing hydrogels because of their biocompatibility and biodegradability. Moreover, they can be introduced with special functional groups and have been successfully applied in many biomedical applications [61, $86,90]$.

\section{Shape memory polymers}

SMPs are polymeric materials that can temporarily fix one or more shapes and later recover to the original shape in response to external stimuli, such as heat, chemicals, $\mathrm{pH}$ value, or light [15]. The shape memory behavior of SMPs is commonly triggered by supramolecular interactions or dynamic covalent bonds. The potential applications of SMPs are displayed in Fig. 3. SMPs undergo uncoupling and recoupling of non-covalent interactions via supramolecular interactions, including hydrogen bonds, host-guest interactions, and metal-ligand coordination. Meanwhile, SMPs rely on dissociation and recombination of dynamic covalent linkages, including boronate ester bond, imine bond, and disulfide bond [16, 91, 92]. Among SMPs, the ones that react to external responsive under physiological conditions have potentials in biomedical applications. The cellular-structured nanofibrous hydrogel was reported to have shape memory ability triggered by water molecules [51]. Boronate ester hydrogel could be designed to have shape memory ability via $\mathrm{pH}$ value variation [52]. The hydrogel composed of N,N-

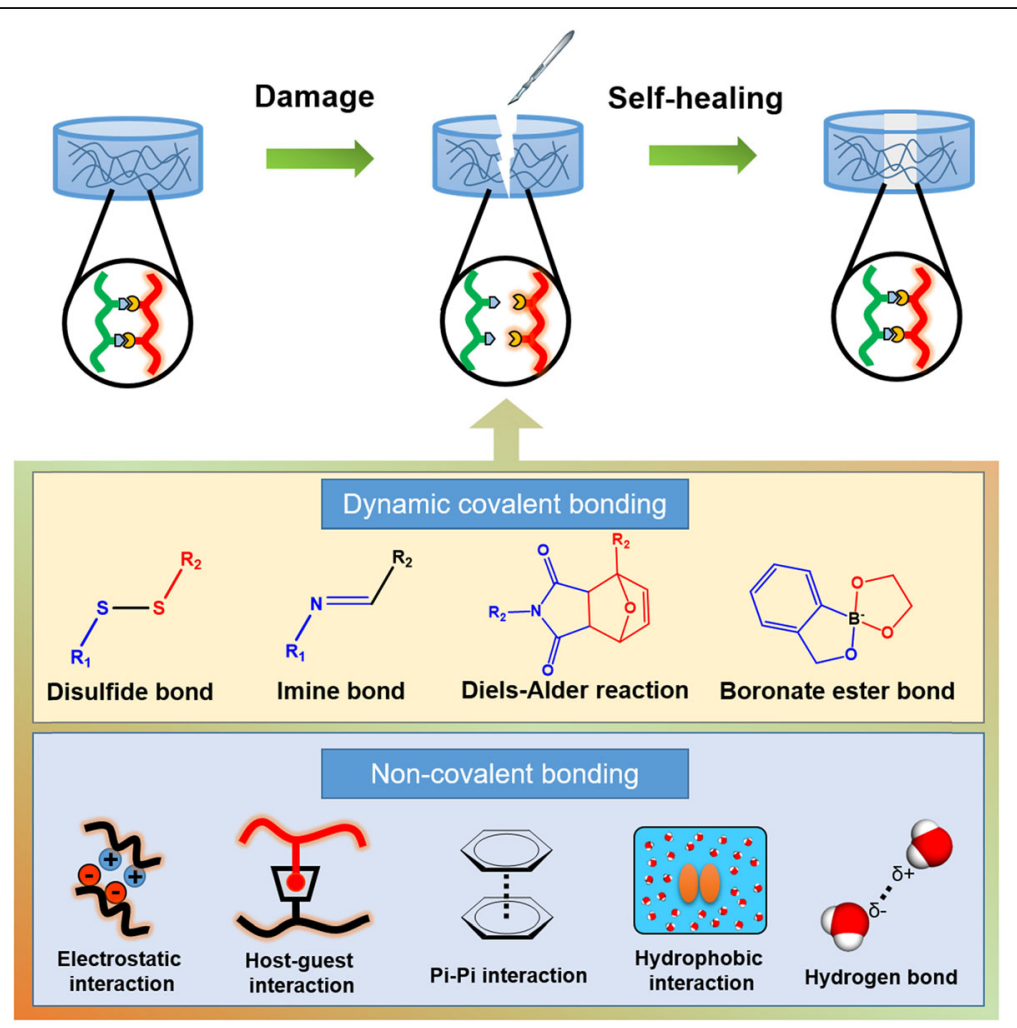

Fig. 2 Categories and healing mechanism of self-healing hydrogels for the design strategies of biomedical applications 


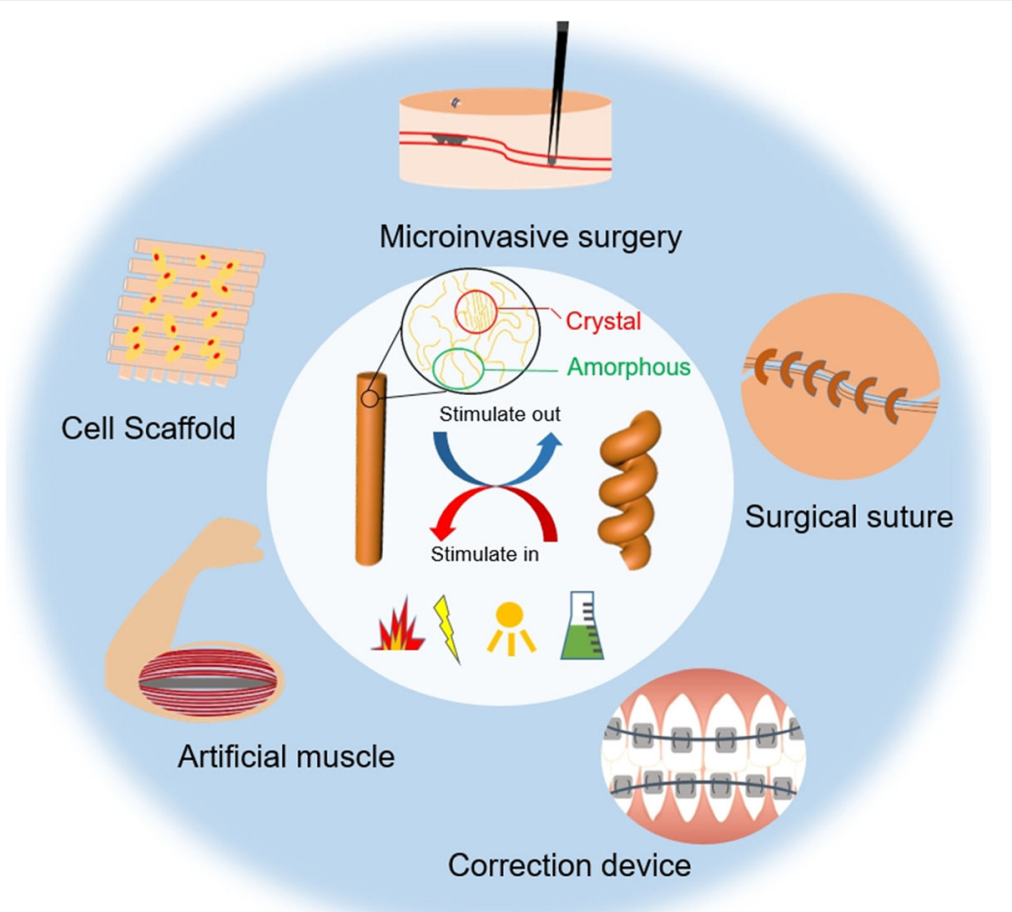

Fig. 3 Schematic overview of shape memory materials, including mechanisms, sources of stimulation, various practical or potential applications

dimethylacrylamide and other acrylate moieties was reported to have the capability of shape memory through exposing to UV light [49]. In previous researches, PU NPs with different oligodiols as the soft segment possess thermal induced shape memory behavior [48, 50]. Briefly, $\mathrm{PU}$ is one of the most competitive shape memory biomaterials for cell therapy and precision medicine owing to the biocompatibility and possibility to print.

\section{Applications of smart polymers for precision medicine}

Smart polymers with tailorable mechanical strength, precise shapes, and environmental responsiveness can be employed to produce scaffolds or stents to provide niche to cater with different types of cells for cell therapy. Smart polymers that possess stimulus-responsiveness can be designed as trigger-release cell/drug/protein carriers. Additive manufacturing (AM) is one fabricating strategy to shorten the distance between materials and cell therapy [93]. Therefore, the following sections will include medical devices, cell therapy, and 3D bioprinting as promising tools to facilitate the realization of precision medicine.

\section{Medical devices}

Medical devices are the devices intended to be used for medical purposes. Among them, scaffolds have been widely studied in decades. The main purpose of fabricating scaffolds is to mimic the extracellular matrix or replace damaged tissues or organs [94]. Many significant successes have already been achieved in almost every tissue, such as heart valves [95], brain [93], retina [96], tracheal tissue [97] and skin [98]. Cell/drug/protein carriers are other typical medical devices for precision medicine. Submicron-sized colloidal particles [99], block copolymer micelle [100], and liposome [101] have been developed as drug vehicles, but they sometimes show limitations in rapid and undesired release or diffusion barrier. One of the most important challenges in medical devices is further enhancing the performance of the scaffold by incorporating smart polymers with stimuli response [102]. The introduction of smart polymers makes these medical devices versatile in biomedical applications. For example, flexible and biodegradable shape memory scaffolds were used for a cardiac patch [102], and stimuli-responsive drug carriers allowed the temporal or spatial control of drug release in the diseased tissues [103]. Moreover, these smart devices are expected to have more advanced applications, such as biomimetic 4D printing [104] or self-folding machines [105]. The shortcomings of these devices are often limited by the precise control, cycles of repetition, and the balance between durability and degradation. In general, smart materials demonstrate the potential for fabricating customized medical devices. 


\section{Cell therapy}

Cell therapy is considered as a promising therapeutic approach in regenerative medicine, which based on utilizing stem, primary or progenitor cells to facilitate the regeneration of damaged tissue or organs. Current cell-based therapy is designed for various prominent disorders, and diseases targeted by cell-based therapies including cardiovascular, neurological, ophthalmologic, skeletal, autoimmune, and so on [106]. Stem cells can differentiate into specifically functional cell types, which have great capability for tissue regeneration and repair in the human body $[107,108]$. Hence, stem cell therapy has emerged as a possible therapeutic strategy because of its inherent self-renewal potential [109]. However, clinical applications of ESCs have ethical challenges and safety concerns [110]. The human embryonic stem cell (hESC) researches contain the destruction of a human embryo, which set a limitation in developing stem cell therapy based on hESC. Besides, immunologic rejection [111] and teratoma formation [112] have safety concerns for the clinical application of stem cells. The induced pluripotent stem cells (iPSCs) technology can avoid the destruction of human embryos and bypass ethical problems, which offers an opportunity to realize precision and personalized medicine [113, 114].

Smart materials can be customized and designed in combination with stem cells and bioprinting. The diagram of transplantation and cell therapy is shown in Fig. 4. The strategy of 3D bioprinting integrates smart materials and stem cells to control cell proliferation or differentiation. Smart materials can change their properties via external stimulations that have the potential to fulfill stem cell differentiation over the past decade [115, 116]. The application of smart materials has been utilized to regulate the differentiation of the stem cells to target cells in response to various external stimulations

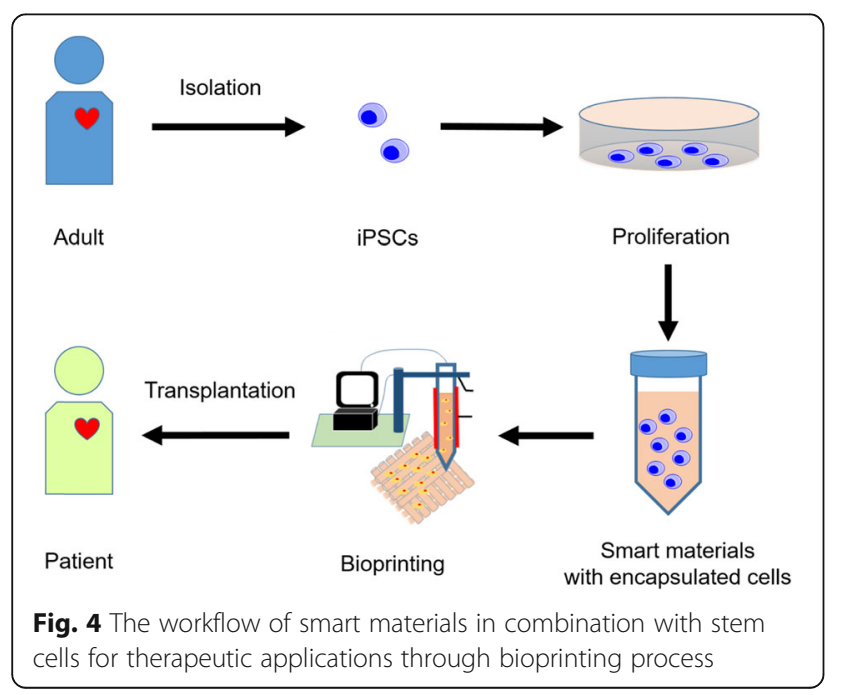

in recent years [117]. The proliferation of stem cells under the specific biological environment conditions can be applied to develop clinical approaches for regeneration and repair of damaged tissues, including cartilage, bone, nerves, fat, and muscle.

Precision biomaterials can be defined as biomaterials designed to target various diseases for individual patients [26]. Customized biomaterials might face challenges that hinder the advancement of designing precision biomaterials such as clinical usages, state of disease, practicality, cost, and approval for use [26]. For instance, the design of smart materials that have the ability to control cellular behavior is a significant challenge in local delivery systems [118]. The lack of biodegradability and biocompatibility might cause adverse effects in strategies of tailored treatment. After implantation of the designed materials to individuals, unwanted inflammation is the major concern that hinders the role of biomimetic approach in the process of precision treatments $[119,120]$.

One of the major challenges is to control the differentiation of stem cells to specific cell types. For instance, recent studies displayed that chitosan-based substrates are effective methods to drive self-renewal, selfassembly, and differentiation of stem cells [121, 122]. By tuning the properties of smart materials, it is possible to regulate the differentiation of stem cells serving as a therapeutic platform for cell-based therapy. Designing smart materials can help stem cells differentiate into specific tissue for tissue regeneration and personalized medicine [123]. Smart materials with self-healing ability can be used in cell printing, which may influence the differentiation of iPSCs to target cells and allow more convenient approach to replace damaged tissue or for applications in minimally invasive surgery [124].

\section{D printing}

$\mathrm{AM}$, commonly known as 3D printing, is a promising technique to fabricate customized shapes or replicate human-scale tissues [82, 125]. Extrusion-based 3D printing is an important tool to perform 3D bioprinting, and this technique is feasible to incorporate high cell density in the aforementioned smart materials [126]. The printing parameters rely on the shearthinning property of the bioink, and the bioink needs to protect the embedded cells when it goes through the nozzle. The crosslinking mechanisms and mechanical properties of bioink also play essential roles in cell viability [127-129]. Collagen and agarose-based bioinks seeded with stem cells are reported to maintain cell viability and induce cell differentiation [130]. GelMA based bioinks show good printability and promote cell proliferation. The mechanical properties of GelMA based bioinks could be tuned based on different crosslinking density, exposure time, and light sources, UV 
light or visible light [73-75]. PU NP bioink also reveals good printability and an appropriate 3D environment for cell culture [8].

Previous studies suggested that bioink can be a versatile platform for different tissue engineering [34, 50, 97, $131,132]$. In addition to bioink, sacrificial 3D printing is an alternative strategy to provide hollow tube constructs for tissue engineering. In the previous studies, the sacrificial materials could be removed due to their environmental responsiveness, including temperature variation and chemical dissolution [133-135]. Moreover, stereolithography (SLA) is another type of 3D printing, which uses light to selectively trigger the polymerization of photopolymers. Synthetic biomaterials, such as poly (D, L-lactide), poly(ethylene glycol) diacrylate, and poly( $\varepsilon$ caprolactone) have been 3D printed via SLA to fabricate scaffolds with high resolution.

\section{Conclusion}

The stimulus-responsive property, shape memory behavior, and self-healing ability of smart polymeric materials are important features for tissue engineering, medical devices, and cell therapy. Precision medicine can be gradually realized with smart polymeric materials considering the "temporal", "spatial", and "personal" aspects. Smart polymeric materials are promising biomedical materials for the development of novel biodegradable or biocompatible scaffolds to fulfill the temporal aspect. Designing smart polymeric materials also helps improve the development of injectable self-healing hydrogels and control-release drug delivery system to carry out the spatial perspective. Last but not least, 3D printing of the bioink that contains patients' stem cells is an important fabricating technique to combine smart polymeric materials and cell therapy to meet the personal aspect. Taken together, the development of smart polymeric materials plays an important role to incorporate all these three aspects for cell therapy and precision medicine.

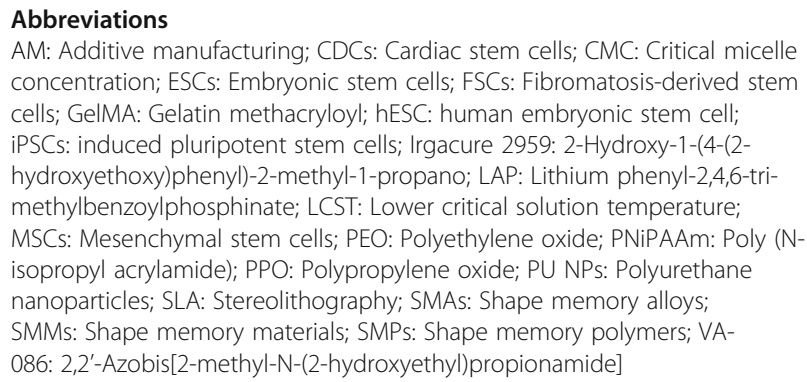

Abbreviations

AM: Additive manufacturing; CDCs: Cardiac stem cells; CMC: Critical micelle concentration; ESCs: Embryonic stem cells; FSCs: Fibromatosis-derived stem cells; GelMA: Gelatin methacryloyl; hESC: human embryonic stem cell; iPSCs: induced pluripotent stem cells; Irgacure 2959: 2-Hydroxy-1-(4-(2hydroxyethoxy)phenyl)-2-methyl-1-propano; LAP: Lithium phenyl-2,4,6-trimethylbenzoylphosphinate; LCST: Lower critical solution temperature; MSCs: Mesenchymal stem cells; PEO: Polyethylene oxide; PNiPAAm: Poly (Nisopropyl acrylamide); PPO: Polypropylene oxide; PU NPs: Polyurethane nanoparticles; SLA: Stereolithography; SMAs: Shape memory alloys; SMMs: Shape memory materials; SMPs: Shape memory polymers; VA086: 2,2'-Azobis[2-methyl-N-(2-hydroxyethyl)propionamide]

\section{Acknowledgements}

We are thankful to Taiwan Bio-development Foundation for assistance.

\section{Authors' contributions}

$\mathrm{H}-\mathrm{J} \mathrm{H}, \mathrm{Y}-\mathrm{L} \mathrm{T}, \mathrm{S}-\mathrm{H} \mathrm{L}$, and $\mathrm{S}-\mathrm{H} \mathrm{H}$ wrote the paper and designed the Figures. All authors read the final manuscript and $\mathrm{S}-\mathrm{H} \mathrm{H}$ approved it for publication.
Funding

Not applicable

Availability of data and materials

Not applicable

Ethics approval and consent to participate

Not applicable

\section{Consent for publication}

Not applicable

\section{Competing interests}

The authors declare that they have no competing interests.

\section{Author details}

${ }^{1}$ Institute of Polymer Science and Engineering, National Taiwan University, No. 1, Sec. 4 Roosevelt Road, Taipei 10617, Taiwan, Republic of China. ${ }^{2}$ Research and Development Center for Medical Devices, National Taiwan University, Taipei, Taiwan. ${ }^{3}$ Institute of Cellular and System Medicine, National Health Research Institutes, No. 35 Keyan Road, Miaoli 35053, Taiwan, Republic of China.

Received: 19 June 2019 Accepted: 1 October 2019

Published online: 18 October 2019

References

1. Aguilar MR, San Román J. Smart polymers and their applications, 2rd ed. Woodhead Publishing; 2019

2. Cobo I, Li M, Sumerlin BS, Perrier S. Smart hybrid materials by conjugation of responsive polymers to biomacromolecules. Nat Mater. 2015;14(2):143-59.

3. Zhu M, Song XZ, Song SY, Zhao SN, Meng X, Wu LL, Wang C, Zhang HJ. A temperature-responsive smart europium metal-organic framework switch for reversible capture and release of intrinsic Eu(3+) ions. Adv Sci (Weinh). 2015;2(4):1500012.

4. Verma R, Adhikary RR, Banerjee R. Smart material platforms for miniaturized devices: implications in disease models and diagnostics. Lab Chip. 2016; 16(11):1978-92.

5. Zhong Y, Zhang F, Wang M, Gardner CJ, Kim G, Liu Y, Leng J, Jin S, Chen R. Reversible humidity sensitive clothing for personal thermoregulation. Sci Rep. 2017;7:44208.

6. Borin D, Stepanov G, Dohmen E. On anisotropic mechanical properties of heterogeneous magnetic polymeric composites. Philos Trans A Math Phys Eng Sci. 2019;377(2143):20180212.

7. Hollingshead S, Lin CY, Liu JC. Designing Smart Materials with Recombinant Proteins. Macromol Biosci. 2017;17(7).

8. Hsiao SH, Hsu SH. Synthesis and characterization of dual stimuli-sensitive biodegradable polyurethane soft hydrogels for 3D cell-laden bioprinting. ACS Appl Mater Interfaces. 2018;10(35):29273-87.

9. Wei M, Gao Y, Li X, Serpe MJ. Stimuli-responsive polymers and their applications. Polym Chem. 2017;8(1):127-43.

10. Sokolov IL, Cherkasov VR, Tregubov AA, Buiucli SR, Nikitin MP. Smart materials on the way to theranostic nanorobots: molecular machines and nanomotors, advanced biosensors, and intelligent vehicles for drug delivery. Biochim Biophys Acta Gen Subj. 2017;1861(6):1530-44.

11. Samui A, Pal K, Karmakar P, Sahu SK. In situ synthesized lactobionic acid conjugated NMOFs, a smart material for imaging and targeted drug delivery in hepatocellular carcinoma. Mater Sci Eng C Mater Biol Appl. 2019; 98:772-81.

12. Tseng TC, Wong CW, Hsieh FY, Hsu SH. Biomaterial Substrate-Mediated Multicellular Spheroid Formation and Their Applications in Tissue Engineering. Biotechnol J. 2017;12(12).

13. Wang S., Lee J.M. and Yeong W.Y. Smart hydrogels for 3D bioprinting International Journal of Bioprinting. 2015;1(1):3-14.

14. Antman EM, Loscalzo J. Precision medicine in cardiology. Nat Rev Cardiol. 2016;13:591

15. Pethe AM, Yadav KS. Polymers, responsiveness and cancer therapy. Artif Cells Nanomed Biotechnol. 2019;47(1):395-405.

16. Liu Y, Hsu SH. Synthesis and biomedical applications of self-healing hydrogels. Front Chem. 2018;6:449. 
17. Zhang Y, Tao L, Li S, Wei Y. Synthesis of multiresponsive and dynamic chitosan-based hydrogels for controlled release of bioactive molecules. Biomacromolecules. 2011;12(8):2894-901.

18. Hsieh F-Y, Tao L, Wei Y, Hsu S.-h. A novel biodegradable self-healing hydrogel to induce blood capillary formation. Npg Asia Materials. 2017;9:e363.

19. Xie W, Gao Q, Guo Z, Wang D, Gao F, Wang X, Wei Y, Zhao L. Injectable and self-healing Thermosensitive magnetic hydrogel for asynchronous control release of doxorubicin and Docetaxel to treat triple-negative breast Cancer. ACS Appl Mater Interfaces. 2017;9(39):33660-73.

20. Hu J, Zhu Y, Huang H, Lu J. Recent advances in shape-memory polymers: structure, mechanism, functionality, modeling and applications. Prog Polym Sci. 2012;37(12):1720-63.

21. Migliavacca F, Petrini L, Massarotti P, Schievano S, Auricchio F, Dubini G. Stainless and shape memory alloy coronary stents: a computational study on the interaction with the vascular wall. Biomech Model Mechanobiol. 2004;2(4):205-17.

22. Small Wt, Singhal P, Wilson TS, Maitland DJ. Biomedical applications of thermally activated shape memory polymers. J Mater Chem. 2010;20(18): 3356-66.

23. Laschi C, Mazzolai B, Cianchetti M. Soft robotics: Technologies and systems pushing the boundaries of robot abilities. Sci. Robot. 2016;1(1):eaah3690.

24. Chan BQY, Low ZWK, Heng SJW, Chan SY, Owh C, Loh XJ. Recent advances in shape memory soft materials for biomedical applications. ACS Appl Mater Interfaces. 2016;8(16):10070-87.

25. Kuang X, Chen K, Dunn CK, Wu J, Li VC, Qi HJ. 3D printing of highly stretchable, shape-memory, and self-healing elastomer toward novel 4D printing. ACS Appl Mater Interfaces. 2018;10(8):7381-8.

26. Chan IS, Ginsburg GS. Personalized medicine: progress and promise. Annu Rev Genomics Hum Genet. 2011;12:217-44.

27. Bhamidipati CM, Coselli JS, LeMaire SA. BioGlue in 2011: what is its role in cardiac surgery? J Extra Corpor Technol. 2012;44(1):P6-12.

28. Tsou $\mathrm{YH}$, Khoneisser J, Huang PC, Xu X. Hydrogel as a bioactive material to regulate stem cell fate. Bioact Mater. 2016;1(1):39-55.

29. Pentlavalli S, Chambers P, Sathy BN, O'Doherty M, Chalanqui M, Kelly DJ, Haut-Donahue T, Mccarthy HO, Dunne NJ. Simple Radical Polymerization of Poly(Alginate-Graft-N-Isopropylacrylamide) Injectable Thermoresponsive Hydrogel with the Potential for Localized and Sustained Delivery of Stem Cells and Bioactive Molecules. Macromol Biosci. 2017:17(11).

30. Wu DQ, Zhu J, Han H, Zhang JZ, Wu FF, Qin XH, Yu JY. Synthesis and characterization of arginine-NIPAAm hybrid hydrogel as wound dressing: in vitro and in vivo study. Acta Biomater. 2018;65:305-16.

31. Wang D, Liu T, Yin J, Liu S. Stimuli-responsive fluorescent poly $(\mathrm{N}$ isopropylacrylamide) microgels labeled with Phenylboronic acid moieties as multifunctional Ratiometric probes for glucose and temperatures. Macromolecules. 2011;44(7):2282-90.

32. Graisuwan W, Puthong S, Zhao H, Kiatkamjornwong S, Theato P, Hoven VP. Thermoresponsive and active functional Fiber Mats for cultured cell recovery. Biomacromolecules. 2017;18(11):3714-25.

33. Ou CW, Su CH, Jeng US, Hsu SH. Characterization of biodegradable polyurethane nanoparticles and thermally induced self-assembly in water dispersion. ACS Appl Mater Interfaces. 2014;6(8):5685-94.

34. Hsieh FY, Lin HH, Hsu SH. 3D bioprinting of neural stem cell-laden thermoresponsive biodegradable polyurethane hydrogel and potential in central nervous system repair. Biomaterials. 2015;71:48-57.

35. Jung Y-S, Park W, Park H, Lee D-K, Na K. Thermo-sensitive injectable hydrogel based on the physical mixing of hyaluronic acid and Pluronic F127 for sustained NSAID delivery. Carbohydr Polym. 2017;156:403-8.

36. Wang X, Huyang G, Palagummi SV, Liu X, Skrtic D, Beauchamp C, Bowen R, Sun J. High performance dental resin composites with hydrolytically stable monomers. Dent Mater. 2018;34(2):228-37.

37. Loessner D, Meinert C, Kaemmerer E, Martine LC, Yue K, Levett PA, Klein TJ, Melchels FP, Khademhosseini A, Hutmacher DW. Functionalization, preparation and use of cell-laden gelatin methacryloyl-based hydrogels as modular tissue culture platforms. Nat Protoc. 2016;11(4):727-46.

38. Han M-E, Kang BJ, Kim S-H, Kim HD, Hwang NS. Gelatin-based extracellular matrix cryogels for cartilage tissue engineering. J Ind Eng Chem. 2017:45:421-9.

39. Byambaa B, Annabi N, Yue K, Trujillo-de SG, Alvarez MM, Jia W, Kazemzadeh-Narbat M, Shin SR, Tamayol A, Khademhosseini A. Bioprinted Osteogenic and Vasculogenic patterns for engineering 3D bone tissue. Adv Healthc Mater. 2017;6(16):1700015.
40. Chen J, An R, Han L, Wang X, Zhang Y, Shi L, Ran R. Tough hydrophobic association hydrogels with self-healing and reforming capabilities achieved by polymeric core-shell nanoparticles. Mater Sci Eng C. 2019;99:460-7.

41. Gulyuz U, Okay O. Self-healing polyacrylic acid hydrogels. Soft Matter. 2013; 9(43):10287-93.

42. Gao L, Zabihi F, Ehrmann S, Hedtrich S, Haag R. Supramolecular nanogels fabricated via host-guest molecular recognition as penetration enhancer for dermal drug delivery. J Control Release. 2019;300:64-72.

43. Lu Y, Liu Z, Yan H, Peng Q, Wang R, Barkey ME, Jeon JW, Wujcik EK. Ultrastretchable conductive polymer complex as a strain sensor with a repeatable autonomous self-healing ability. ACS Appl Mater Interfaces. 2019.

44. Mistry L, El-Zubir O, Dura G, Clegg W, Waddell PG, Pope T, Hofer WA, Wright NG, Horrocks BR, Houlton A. Addressing the properties of "Metallo-DNA" with a Ag(i)-mediated supramolecular duplex. Chem Sci. 2019;10(11):3186-95.

45. Li T, Zheng T, Han J, Liu Z, Guo ZX, Zhuang Z, Xu J, Guo AB. Effects of Diisocyanate Structure and Disulfide Chain Extender on Hard Segmental Packing and Self-Healing Property of Polyurea Elastomers. Polymers (Basel). 2019;11(5):838.

46. Kim SW, Kim DY, Roh HH, Kim HS, Lee JW, Lee KY. Three-dimensional bioprinting of cell-laden constructs using polysaccharide-based self-healing hydrogels. Biomacromolecules. 2019:20(5):1860-6.

47. Oh CR, Lee SH, Park JH, Lee DS. Thermally Self-Healing GrapheneNanoplate/Polyurethane Nanocomposites via Diels(-)Alder Reaction through a One-Shot Process. Nanomaterials (Basel). 2019;9(3):434.

48. Chien YC, Chuang WT, Jeng US, Hsu SH. Preparation, characterization, and mechanism for biodegradable and biocompatible polyurethane shape memory elastomers. ACS Appl Mater Interfaces. 2017;9(6):5419-29.

49. Argun A, Gulyuz U, Okay O. Interfacing soft and hard materials with tripleshape-memory and self-healing functions. Macromolecules. 2018;51(7): 2437-46.

50. Wang Y-J, Jeng US, Hsu S.-h. Biodegradable water-based polyurethane shape memory elastomers for bone tissue engineering. ACS Biomater Sci Eng. 2018;4(4):1397-406

51. Si Y, Wang L, Wang $X$, Tang N, Yu J, Ding B. Ultrahigh-Water-Content, Superelastic, and Shape-Memory Nanofiber-Assembled Hydrogels Exhibiting Pressure-Responsive Conductivity. Adv Mater. 2017:29(24):1700339.

52. Li Z, Lu W, Ngai T, Le X, Zheng J, Zhao N, Huang Y, Wen X, Zhang J, Chen T. Mussel-inspired multifunctional supramolecular hydrogels with selfhealing, shape memory and adhesive properties. Polym Chem. 2016;7(34): 5343-6.

53. Pitto-Barry A, Barry NPE. Pluronic ${ }^{\oplus}$ block-copolymers in medicine: from chemical and biological versatility to rationalisation and clinical advances. Polym Chem. 2014;5(10):3291-7.

54. Alexandridis P. Poly(ethylene oxide)/poly(propylene oxide) block copolymer surfactants. Curr Opin Colloid Interface Sci. 1997;2(5):478-89.

55. Teotia AK, Sami H, Kumar A. 1 - thermo-responsive polymers: structure and design of smart materials. In: Zhang Z, editor. Switchable and responsive surfaces and materials for biomedical applications. Oxford: Woodhead Publishing; 2015. p. 3-43.

56. Shah T, Halacheva S. 6 - drug-releasing textiles. In: van Langenhove L, editor. Advances in smart medical textiles. Oxford: Woodhead Publishing; 2016. p. 119-54

57. Akash MS, Rehman K. Recent progress in biomedical applications of Pluronic (PF127): pharmaceutical perspectives. J Control Release. 2015; 209:120-38.

58. Khaliq NU, Park DY, Yun BM, Yang DH, Jung YW, Seo JH, Hwang CS, Yuk SH. Pluronics: intelligent building units for targeted cancer therapy and molecular imaging. Int J Pharm. 2019;556:30-44.

59. Nguyen KT, Vinh Le D, Ho DD, Huan Le Q. Development of chitosan graft pluronic ${ }^{\circledR}$ F127 copolymer nanoparticles containing DNA aptamer for paclitaxel delivery to treat breast cancer cells. Adv Nat Sci Nanosci Nanotechnol. 2016:7(2):025018.

60. Sun Y-N, Gao G-R, Du G-L, Cheng Y-J, Fu J. Super tough, Ultrastretchable, and Thermoresponsive hydrogels with functionalized Triblock copolymer micelles as macro-cross-linkers. ACS Macro Lett. 2014;3(5):496-500.

61. Qu J, Zhao X, Liang Y, Zhang T, Ma PX, Guo B. Antibacterial adhesive injectable hydrogels with rapid self-healing, extensibility and compressibility as wound dressing for joints skin wound healing. Biomaterials. 2018;183: 185-99.

62. Deng Z, Hu T, Lei Q, He J, Ma PX, Guo B. Stimuli-responsive conductive Nanocomposite hydrogels with high Stretchability, self-healing, 
adhesiveness, and 3D printability for human motion sensing. ACS Appl Mater Interfaces. 2019;11(7):6796-808.

63. Ruskowitz ER, DeForest CA. Photoresponsive biomaterials for targeted drug delivery and 4D cell culture. Nature Rev Mater. 2018;3:17087.

64. Lin CH, Lin KF, Mar K, Lee SY, Lin YM. Antioxidant N-Acetylcysteine and glutathione increase the viability and proliferation of MG63 cells encapsulated in the gelatin methacrylateNA-086/blue light hydrogel system. Tissue Eng Part C Methods. 2016;22(8):792-800.

65. Tan VTG, Nguyen DHT, Utama RH, Kahram M, Ercole F, Quinn JF, Whittaker MR, Davis TP, Justin GJ. Modular photo-induced RAFT polymerised hydrogels via thiol-ene click chemistry for 3D cell culturing. Polym Chem. 2017;8(39):6123-33.

66. Chartrain NA, Williams CB, Whittington AR. A review on fabricating tissue scaffolds using vat photopolymerization. Acta Biomater. 2018;74:90-111.

67. Bao C, Zhu L, Lin Q, Tian H. Building biomedical materials using photochemical bond cleavage. Adv Mater. 2015;27(10):1647-62.

68. Ligon-Auer SC, Schwentenwein M, Gorsche C, Stampfl J, Liska R. Toughening of photo-curable polymer networks: a review. Polym Chem. 2016;7(2):257-86.

69. Randolph LD, Palin WM, Leloup G, Leprince JG. Filler characteristics of modern dental resin composites and their influence on physico-mechanical properties. Dent Mater. 2016;32(12):1586-99.

70. Graisuwan W, Zhao H, Kiatkamjornwong S, Theato P, Hoven VP. Formation of thermo-sensitive and cross-linkable micelles by self-assembly of poly(pentafluorophenyl acrylate)-containing block copolymer. J Polym Sci A Polym Chem. 2015;53(9):1103-13.

71. Couturaud B, Georgiou PG, Varlas S, Jones JR, Arno MC, Foster JC, O'Reilly RK. Poly(Pentafluorophenyl methacrylate)-based Nano-objects developed by photo-PISA as scaffolds for post-polymerization functionalization. Macromol Rapid Commun. 2019;40(2):e1800460.

72. Ikejiri S, Takashima Y, Osaki M, Yamaguchi H, Harada A. Solvent-free Photoresponsive artificial muscles rapidly driven by molecular machines. J Am Chem Soc. 2018;140(49):17308-15.

73. Noshadi I, Hong S, Sullivan KE, Shirzaei SE, Portillo-Lara R, Tamayol A, Shin SR, Gao AE, Stoppel WL, Black lii LD, Khademhosseini A, Annabi N. In vitro and in vivo analysis of visible light crosslinkable gelatin methacryloyl (GelMA) hydrogels. Biomater Sci. 2017;5(10):2093-105.

74. Liu W, Heinrich MA, Zhou Y, Akpek A, Hu N, Liu X, Guan X, Zhong Z, Jin X, Khademhosseini A, Zhang YS. Extrusion Bioprinting of Shear-Thinning Gelatin Methacryloyl Bioinks. Adv Healthc Mater. 2017;6(12).

75. Stratesteffen $H$, Kopf M, Kreimendahl F, Blaeser A, Jockenhoevel S, Fischer H. GelMA-collagen blends enable drop-on-demand 3D printablility and promote angiogenesis. Biofabrication. 2017;9(4):045002.

76. Pepelanova I, Kruppa K, Scheper T, Lavrentieva A. Gelatin-Methacryloyl (GelMA) Hydrogels with Defined Degree of Functionalization as a Versatile Toolkit for 3D Cell Culture and Extrusion Bioprinting. Bioengineering (Basel). 2018:5(3):55.

77. Koshy ST, Ferrante TC, Lewin SA, Mooney DJ. Injectable, porous, and cellresponsive gelatin cryogels. Biomaterials. 2014;35(8):2477-87.

78. Taylor DL. and In Het Panhuis M. Self-Healing Hydrogels. Adv Mater. 2016; 28(41):9060-93.

79. Bekas DG, Tsirka K, Baltzis D, Paipetis AS. Self-healing materials: a review of advances in materials, evaluation, characterization and monitoring techniques. Compos Part B. 2016;87:92-119.

80. Montano V, Picken SJ, van der Zwaag S, Garcia SJ. A deconvolution protocol of the mechanical relaxation spectrum to identify and quantify individual polymer feature contributions to self-healing. Phys Chem Chem Phys. 2019; 21(19):10171-84

81. Li N, Liu C, Chen W. Facile access to guar gum based Supramolecular hydrogels with rapid self-healing ability and multistimuli responsive gel-sol transitions. J Agric Food Chem. 2019;67(2):746-52.

82. Malda J, Visser J, Melchels FP, Jüngst T, Hennink WE, Dhert WJ, Groll J, Hutmacher DW. 25th anniversary article: engineering hydrogels for biofabrication. Adv Mater. 2013;25(36):5011-28.

83. Darabi MA, Khosrozadeh A, Mbeleck R, Liu Y, Chang Q, Jiang J, Cai J, Wang Q, Luo G, Xing M. Skin-inspired multifunctional autonomic-intrinsic conductive self-healing hydrogels with pressure sensitivity, stretchability, and 3D printability. Adv Mater. 2017;29(31):1700533.

84. Chen H, Cheng J, Ran L, Yu K, Lu B, Lan G, Dai F, Lu F. An injectable selfhealing hydrogel with adhesive and antibacterial properties effectively promotes wound healing. Carbohydr Polym. 2018;201:522-31.
85. Dong R, Zhao X, Guo B, Ma PX. Self-healing conductive injectable hydrogels with antibacterial activity as cell delivery carrier for cardiac cell therapy. ACS Appl Mater Interfaces. 2016:8(27):17138-50.

86. Qu J, Zhao X, Ma PX, Guo B. pH-responsive self-healing injectable hydrogel based on $\mathrm{N}$-carboxyethyl chitosan for hepatocellular carcinoma therapy. Acta Biomater. 2017:58:168-80.

87. Sinclair A, O'Kelly MB, Bai T, Hung HC, Jain P, Jiang S. Self-healing Zwitterionic microgels as a versatile platform for malleable cell constructs and injectable therapies. Adv Mater. 2018;30(39):1803087.

88. Zhao F, Wu D, Yao D, Guo R, Wang W, Dong A, Kong D, Zhang J. An injectable particle-hydrogel hybrid system for glucose-regulatory insulin delivery. Acta Biomater. 2017;64:334-45.

89. Han L, Lu X, Wang M, Gan D, Deng W, Wang K, Fang L, Liu K, Chan CW, Tang Y. A mussel-inspired conductive, self-adhesive, and self-healable tough hydrogel as cell stimulators and implantable bioelectronics. Small. 2017; 13(2):1601916

90. Tseng TC, Tao L, Hsieh FY, Wei Y, Chiu IM, Hsu SH. An injectable, selfhealing hydrogel to repair the central nervous system. Adv Mater. 2015; 27(23):3518-24

91. Xie T. Tunable polymer multi-shape memory effect. Nature. 2010;464(7286):267-70.

92. Lu W, Le X, Zhang J, Huang Y, Chen T. Supramolecular shape memory hydrogels: a new bridge between stimuli-responsive polymers and supramolecular chemistry. Chem Soc Rev. 2017;46(5):1284-94.

93. Lancaster MA, Renner M, Martin CA, Wenzel D, Bicknell LS, Hurles ME, Homfray T, Penninger JM, Jackson AP, Knoblich JA. Cerebral organoids model human brain development and microcephaly. Nature. 2013; 501(7467):373-9.

94. Asghari F, Samiei M, Adibkia K, Akbarzadeh A, Davaran S. Biodegradable and biocompatible polymers for tissue engineering application: a review. Artif Cells Nanomed Biotechnol. 2017:45(2):185-92.

95. Fallahiarezoudar E, Ahmadipourroudposht M, Idris A, Mohd YN. A review of: application of synthetic scaffold in tissue engineering heart valves. Mater $\mathrm{Scl}$ Eng C Mater Biol Appl. 2015;48:556-65.

96. Singh D, Wang SB, Xia T, Tainsh L, Ghiassi-Nejad M, Xu T, Peng S, Adelman RA, Rizzolo LJ. A biodegradable scaffold enhances differentiation of embryonic stem cells into a thick sheet of retinal cells. Biomaterials. 2018;154:158-68.

97. Hsieh C-T, Liao C-Y, Dai N-T, Tseng C-S, Yen BL, Hsu S.-h. 3D printing of tubular scaffolds with elasticity and complex structure from multiple waterborne polyurethanes for tracheal tissue engineering. Appl Mater Today. 2018;12:330-41.

98. Ge J, Sun L, Zhang FR, Zhang Y, Shi LA, Zhao HY, Zhu HW, Jiang HL, Yu SH. A stretchable electronic fabric artificial skin with pressure-, lateral strain-, and flexion-sensitive properties. Adv Mater. 2016;28(4):722-8.

99. Danhier F, Lecouturier N, Vroman B, Jerome C, Marchand-Brynaert J, Feron $\mathrm{O}$, Preat V. Paclitaxel-loaded PEGylated PLGA-based nanoparticles: in vitro and in vivo evaluation. J Control Release. 2009;133(1):11-7.

100. Huh KM, Min HS, Lee SC, Lee HJ, Kim S, Park K. A new hydrotropic block copolymer micelle system for aqueous solubilization of paclitaxel. J Control Release. 2008;126(2):122-9.

101. Sercombe L, Veerati T, Moheimani F, Wu SY, Sood AK, Hua S. Advances and challenges of liposome assisted drug delivery. Front Pharmacol. 2015;6:286.

102. Montgomery M, Ahadian S, Davenport HL, Lo RM, Civitarese RA, Vanderlaan RD, Wu J, Reis LA, Momen A, Akbari S, Pahnke A, Li RK, Caldarone CA, Radisic M. Flexible shape-memory scaffold for minimally invasive delivery of functional tissues. Nat Mater. 2017;16(10):1038-46.

103. Ramasamy T, Ruttala HB, Gupta B, Poudel BK, Choi HG, Yong CS, Kim JO. Smart chemistry-based nanosized drug delivery systems for systemic applications: a comprehensive review. J Control Release. 2017;258:226-53.

104. Gladman AS, Matsumoto EA, Nuzzo RG, Mahadevan L, Lewis JA. Biomimetic 4D printing. Nat Mater. 2016;15(4):413-8.

105. Felton S, Tolley M, Demaine E, Rus D, Wood R. Applied origami. A method for building self-folding machines. Science. 2014;345(6197):644-6.

106. Buzhor E, Leshansky L, Blumenthal J, Barash H, Warshawsky D, Mazor Y, Shtrichman R. Cell-based therapy approaches: the hope for incurable diseases. Regen Med. 2014;9(5):649-72.

107. Peng BY, Dubey NK, Mishra VK, Tsai FC, Dubey R, Deng WP, Wei HJ. Addressing stem cell therapeutic approaches in pathobiology of diabetes and its complications. J Diabetes Res. 2018:2018:7806435.

108. Labusca L, Herea DD, Mashayekhi K. Stem cells as delivery vehicles for regenerative medicine-challenges and perspectives. World J Stem Cells. 2018;10(5):43-56. 
109. Blau HM, Brazelton TR, Weimann JM. The evolving concept of a stem cell: entity or function? Cell. 2001;105(7):829-41.

110. Volarevic V, Markovic BS, Gazdic M, Volarevic A, Jovicic N, Arsenijevic N, Armstrong L, Djonov V, Lako M, Stojkovic M. Ethical and safety issues of stem cell-based therapy. Int J Med Sci. 2018;15(1):36-45.

111. Taylor CJ, Bolton EM, Bradley JA. Immunological considerations for embryonic and induced pluripotent stem cell banking. Philos Trans R Soc Lond Ser B Biol Sci. 2011;366(1575):2312-22.

112. Wood EH, Tang PH, De la Huerta I, Korot E, Muscat S, Palanker DA, Williams GA. STEM CELL THERAPIES, GENE-BASED THERAPIES, OPTOGENETICS, AND RETINAL PROSTHETICS: current state and implications for the future. Retina. 2019;39(5):820-35.

113. Sayed N, Ameen M, Wu JC. Personalized medicine in cardio-oncology: the role of induced pluripotent stem cell. Cardiovasc Res. 2019;115(5):949-59.

114. Haridhasapavalan KK, Borgohain MP, Dey C, Saha B, Narayan G, Kumar S, Thummer RP. An insight into non-integrative gene delivery approaches to generate transgene-free induced pluripotent stem cells. Gene. 2019;686:146-59.

115. Dawson E, Mapili G, Erickson K, Taqvi S, Roy K. Biomaterials for stem cell differentiation. Adv Drug Deliv Rev. 2008;60(2):215-28.

116. Singh A, Elisseeff J. Biomaterials for stem cell differentiation. J Mater Chem. 2010:20(40):8832-47.

117. Zhang J., Zhang H. and Xu X. CHAPTER 17 Smart Materials to Regulate the Fate of Stem Cells. Smart Materials for Tissue Engineering: Applications. The Royal Society of Chemistry, 2017, pp. 473-504.

118. Cantley WL, Du C, Lomoio S, DePalma T, Peirent E, Kleinknecht D, Hunter M, Tang-Schomer MD, Tesco G, Kaplan DL. Functional and sustainable 3D human neural network models from pluripotent stem cells. ACS Biomater Sci Eng. 2018;4(12):4278-88.

119. Crupi A, Costa A, Tarnok A, Melzer S, Teodori L. Inflammation in tissue engineering: the Janus between engraftment and rejection. Eur I Immunol. 2015;45(12):3222-36.

120. Gu Z. Introduction to special issue on "responsive materials and systems: toward smart and precision medications". Bioeng Transl Med. 2016;1(3):235-6

121. Aljawish A, Muniglia L, Chevalot I. Growth of human mesenchymal stem cells (MSCs) on films of enzymatically modified chitosan. Biotechnol Prog. 2016;32(2):491-500.

122. Tang Q, Luo C, Lu B, Fu Q, Yin H, Qin Z, Lyu D, Zhang L, Fang Z, Zhu Y, Yao K. Thermosensitive chitosan-based hydrogels releasing stromal cell derived factor-1 alpha recruit MSC for corneal epithelium regeneration. Acta Biomater. 2017:61:101-13.

123. Damaraju SM, Shen Y, Elele E, Khusid B, Eshghinejad A, Li J, Jaffe M, Arinzeh TL. Three-dimensional piezoelectric fibrous scaffolds selectively promote mesenchymal stem cell differentiation. Biomaterials. 2017;149:51-62.

124. Lipskas J, Deep K, Yao W. Robotic-assisted 3D bio-printing for repairing bone and cartilage defects through a minimally invasive approach. Sci Rep. 2019:9(1):3746

125. Lee J-Y, An J, Chua CK. Fundamentals and applications of 3D printing for novel materials. Appl Mater Today. 2017;7:120-33.

126. Ozbolat IT, Hospodiuk M. Current advances and future perspectives in extrusion-based bioprinting. Biomaterials. 2016;76:321-43.

127. Guvendiren M, Molde J, Soares RM, Kohn J. Designing biomaterials for 3D printing. ACS Biomater Sci Eng. 2016;2(10):1679-93.

128. Kyle S, Jessop ZM, Al-Sabah A, Whitaker IS. 'Printability' of Candidate Biomaterials for Extrusion Based 3D Printing: State-of-the-Art. Adv Healthc Mater. 2017;6(16).

129. Jungst T, Smolan W, Schacht K, Scheibel T, Groll J. Strategies and molecular design criteria for 3D printable hydrogels. Chem Rev. 2016;116(3):1496-539.

130. Duarte Campos DF, Blaeser A, Korsten A, Neuss S, Jakel J, Vogt M, Fischer H. The stiffness and structure of three-dimensional printed hydrogels direct the differentiation of mesenchymal stromal cells toward adipogenic and osteogenic lineages. Tissue Eng Part A. 2015;21(3-4):740-56

131. Hung KC, Tseng CS, Hsu SH. Synthesis and 3D printing of biodegradable polyurethane elastomer by a water-based process for cartilage tissue engineering applications. Adv Healthc Mater. 2014;3(10):1578-87.

132. Ho L, Hsu SH. Cell reprogramming by 3D bioprinting of human fibroblasts in polyurethane hydrogel for fabrication of neural-like constructs. Acta Biomater. 2018;70:57-70.

133. Compaan AM, Christensen K, Huang Y. Inkjet bioprinting of 3D silk fibroin cellular constructs using sacrificial alginate. ACS Biomater Sci Eng. 2017;3(8):1519-26.
134. Contessi NN, Bonnetier M, Giatsidis G, Orgill DP, Farè S, Marelli B. Tissuemimicking gelatin scaffolds by alginate sacrificial templates for adipose tissue engineering. Acta Biomater. 2019;87:61-75.

135. Miri AK, Khalilpour A, Cecen B, Maharjan S, Shin SR, Khademhosseini A. Multiscale bioprinting of vascularized models. Biomaterials. 2019;198:204-16.

\section{Publisher's Note}

Springer Nature remains neutral with regard to jurisdictional claims in published maps and institutional affiliations.
Ready to submit your research? Choose BMC and benefit from:

- fast, convenient online submission

- thorough peer review by experienced researchers in your field

- rapid publication on acceptance

- support for research data, including large and complex data types

- gold Open Access which fosters wider collaboration and increased citations

- maximum visibility for your research: over $100 \mathrm{M}$ website views per year

At BMC, research is always in progress.

Learn more biomedcentral.com/submissions 